\title{
The Influence of Stone Size, Skin to Stone Distance and Hydronephrosis on Extracorporeal Shock Wave Lithotripsy Session and Shock Wave Numbers in Ureteral Stones
}

\author{
Basri Cakiroglu ${ }^{\mathrm{a}, \mathrm{g}}$, Erkan Eyyupoglu ${ }^{\mathrm{b}}$, Tuncay Tas ${ }^{\mathrm{c}}$, Orhun Sinanoglu ${ }^{\mathrm{d}}$, Ismet Hazarc, \\ M. Bahadir Can Balcic, Suleyman Hilmi Aksoy ${ }^{\mathrm{e}}$, Bekir Sami Uyanik ${ }^{\mathrm{f}}$
}

\begin{abstract}
Background: To evaluate the impact of stone size, grade of hydronephrosis induced by the stone and skin to stone distance (SSD) on the shock wave lithotripsy (SWL) outcome in terms of SWL session and shock wave (SW) numbers in patients with ureteral stones.

Methods: Between June 2011 and December 2011, data of 80 patients undergoing SWL for ureteral stones were retrospectively reviewed. Patients were classified into three groups according to hydronephrotic grades (group 1, grade 1 hydronephrosis; group 2, grade 2 hydronephrosis; group 3, grade 3 hydronephrosis) and into two groups according to stone size (group 1, stone size $\leq 10 \mathrm{~mm}$ and group 2, stone size $>10 \mathrm{~mm}$ ). The effect of hydronephrotic grade, SSD and stone size on SWL sessions and SW rates were studied. The impact of the stone size on hydronephrosis was also analyzed.
\end{abstract}

Result: Of the 80 patients undergoing SWL, 24 were female and 56 were male. The mean age, stone size, number of sessions, SW rate and SSD were 37.7 (16 - 73), $9.6 \mathrm{~mm}$ (6 - 19), 1.65 (1 - 4), 3,812 $(1,200-8,500)$ and $9.6 \mathrm{~cm}(5-15)$ respectively. Thirty-five patients had grade 1, 29 grade 2 and 16 grade 3 hydronephrosis. Twentyeight patients had upper, $19 \mathrm{mid}$ and 33 lower ureteral stones. There were significant correlation between stone size and SW number $(\mathrm{r}$

Manuscript accepted for publication November 15, 2013

${ }^{a}$ Department of Urology, Hisar Intercontinental Hospital, Saray Mah. Siteyolu Cad. No. 7, 34768 Umraniye, Istanbul, Turkey

${ }^{\mathrm{b}}$ Department of Urology, Sabuncuoglu Serafettin Amasya Teaching and Research Hospital, Amasya, Turkey

${ }^{\mathrm{c}}$ Department of Urology, Taksim Training and Research Hospital,

Taksim, Istanbul, Turkey

${ }^{\mathrm{d}}$ Maltepe University Medical School Department of Urology, Istanbul,

Turkey

e Department of Radiology, Hisar Intercontinental Hospital, Saray Mah. Siteyolu Cad. No. 7, 34768 Umraniye, Istanbul, Turkey

${ }^{\mathrm{f}}$ Department of Clinical Biochemistry, Hisar Intercontinental Hospital, Saray Mah. Siteyolu Cad. No. 7, 34768 Umraniye, Istanbul, Turkey

${ }^{\mathrm{g}}$ Corresponding author: Basri Cakiroglu, Department of Urology, Hisar Intercontinental Hospital, Saray Mah. Siteyolu Cad. No. 7, 34768

Umraniye, Istanbul, Turkey. Email: drbasri@gmail.com

doi: http://dx.doi.org/10.4021/wjnu127w
$=0.513, \mathrm{P}<0.001)$, and between stone size and session number $(\mathrm{r}$ $=0.609, \mathrm{P}<0.001)$. The correlation between hydronephrotic grade, SW and session numbers was also significant $(\mathrm{r}=0.472, \mathrm{P}<0.001$ and $\mathrm{r}=0.441, \mathrm{P}<0.001)$. There was no correlation between SSD and SW and session numbers. Four patients with stone size more than $10 \mathrm{~mm}$ and grade 2-3 hydronephrosis had unsuccessful SWL outcome.

Conclusion: The grade of hydronephrosis and stone size are independent predictive factors for SW and SWL session numbers and indirectly for treatment outcome. SSD was not found to be predictive.

Keywords: Ureteral stone; SWL; Hydronephrosis; Stone size; Skin to stone distance

\section{Introduction}

Urinary stone disease is the third entity following urinary tract infection and prostate diseases among urinary disorders [1]. Before the period where shock wave lithotripsy (SWL) entered therapeutic use in 1980s invasive methods had been used in urolithiasis treatment [2]. Today more than $90 \%$ of urolithiasis cases are treated with SWL [3]. However, stones may not be fragmented by SWL in some of the patients. Failure of SWL is more common with ureteral stones larger than $10 \mathrm{~mm}$ therefore invasive additional treatment methods are necessary in these cases [4]. The success rate is influenced by stone factors (stone size, location, composition, degree of obstruction), clinical factors (comorbidities such as concomitant infection, solitary kidney, abnormal ureteral anatomy), and technical factors (available equipment, source of energy) [5]. Several factors influencing stone clearance and success rate such as body mass index (BMI), skin to stone distance (SSD), Hounsfield unit of the stone and the grade of hydronephrosis are studied widely $[6,7]$. There are controversial reports in different studies and it is not certain which factors among the studied parameters effect the outcome of SWL. Thus, we investigated the predictive factors of SWL outcomes in terms of SWL session and shock wave (SW) numbers, including grade of hydronephrosis, SSD and stone size in the treatment of ureteral stones. Additionally, the im- 
Table 1. Variables in Hydronephrotic Grades (Mean \pm SD)

\begin{tabular}{llll}
\hline & Grade 1 $(\mathbf{N}=\mathbf{3 5})$ & Grade 2 $(\mathbf{N}=\mathbf{2 8})$ & Grade 3 (N= 17) \\
\hline Age (years) & $35.7 \pm 8.5$ & $38.5 \pm 14.2$ & $40.6 \pm 14.2$ \\
Gender (m/f) & $24 / 11$ & $21 / 7$ & $11 / 6$ \\
Stone size (mm) & $8.7 \pm 2.6$ & $9.6 \pm 3.1$ & $11.7 \pm 3.7^{* * * *}$ \\
SWL shocks' number & $2,821 \pm 1,694$ & $3,835 \pm 1,949 *$ & $5,666 \pm 2,381^{*} * *$ \\
SWL sessions' number & $1.3 \pm 0.5$ & $1.7 \pm 0.8 *$ & $2.3 \pm 1.1^{*}$ \\
Skin-stone distance (cm) & $9.5 \pm 1.9$ & $9.6 \pm 2.3$ & $9.9 \pm 1.5$ \\
\hline
\end{tabular}

$\mathrm{P}<0.05$, " $c o m p a r e d$ to grade $1,{ }^{* *}$ compared to grade 2 (Mann-Whitney $\mathrm{U}$ ).

pact of the tone size on hydronephrosis was also evaluated.

\section{Materials and Methods}

Between June 2011 and December 2011, data of 80 patients undergoing SWL for ureteral stone were retrospectively reviewed. Non-enhanced computed tomography (NECT) was used in the diagnosis. The inclusion criteria were stone size $>4 \mathrm{~mm}$ and stones that were solitary. Patients with urinary tract infections, blood coagulation disorders, ureteral stricture, neurogenic bladder, or polycystic kidney and pregnancy were excluded. Patients were classified into three groups according to hydronephrotic grades (group 1, grade 1 hydronephrosis; group 2, grade 2 hydronephrosis; group 3, grade 3 hydronephrosis) and into two groups according to stone size (group 1, stone size $\leq 10 \mathrm{~mm}$ and group 2, stone size $>10$ $\mathrm{mm})$. The SSD was measured on NECT by three distances from the stone to the skin $\left(0^{\circ}, 45^{\circ}\right.$ and $\left.90^{\circ}\right)$. The average SSD was measured from these values and was recorded as the representative SSD for each stone. SWL was performed with Storz Medical Modulith SLK. The stones were focused with ultrasound (US) guidance, and the number of SWs and energy levels were recorded. A maximum of 3,500 SWs with maximal power $24 \mathrm{kV}$ per session were delivered within 1 - 4 (mean 1.7) sessions. The grades of hydronephrosis were measured with SWL device's US focusing probe. The result of treatment was evaluated by plain radiography and/or ultrasound at 1 or 2 weeks after each SWL. When there was a large fragment with a long diameter $>4 \mathrm{~mm}$, SWL was repeated until each fragment became smaller than $4 \mathrm{~mm}$. The failure of SWL was defined as remnant stones larger than $4 \mathrm{~mm}$ at 3 months were present after the first session. The influences of hydronephrotic grade, SSD and stone size on SWL parameters were studied. Treatment failure was defined in case of incomplete fragmentation or clearance. The results in all groups were evaluated and the predictive fac- tors analyzed. Statistical analysis was performed by using SPSS ver. 16.0 (SPSS Inc., Chicago, IL, USA). Analysis of the mean values of the variables was performed using MannWhitney $U$ and independent sample $t$ test, the strength of the linear relationship between two variables was analyzed with Pearson correlation as appropriate. Values of $\mathrm{P}<0.05$ were considered statistically significant.

\section{Results}

Of 80 patients undergoing ESWL, there were 24 females and 56 males. The mean age, stone size and SSD were 37.7 (16 - 73), $9.6 \mathrm{~mm}(6-19)$ and $9.6 \mathrm{~cm}(5-15)$ respectively. Thirty-five patients had grade 1, 29 grade 2 and 16 grade 3 hydronephrosis (Table 1). Twenty-eight patients had upper, 19 had mid and 33 had lower ureteral stones. Stones of 76 patients $(95 \%)$ were totally cleared, four patients $4(5 \%)$ with stone size $>10 \mathrm{~mm}$ and grade 2-3 hydronephrosis had unsuccessful SWL outcome. They required additional treatment as two stones could not be fragmented and, in other two, steinstrasse complication ensued. All of these patients with steinstrasse had to undergo ureterorenoscopic lithotripsy. Among these 4 unsuccessful SWL cases three patients had proximal ureteral stones and, one mid ureteral stone all of which were greater than $10 \mathrm{~mm}$ in size. Mean SW number and session number in patients with grade 3 hydronephrosis were higher compared to that of grade 1 hydronephrosis $(\mathrm{P}$ $<0.001)$. Mean SW number and session number in patients with grade 2 hydronephrosis were also higher compared to that of grade 1 hydronephrosis $(\mathrm{P}<0.05)$ (Table 1) (Fig. 1). Mean SW number and session number in patients with stones $>10 \mathrm{~mm}$ were higher compared to that with stones $\leq 10 \mathrm{~mm}$ $(\mathrm{P}<0.05)$ (Table 2). The mean stone size in grade 3 hydronephrosis was $11.7 \pm 3.7 \mathrm{~mm}$ versus $8.7 \pm 2.6 \mathrm{~mm}$ and $9.6 \pm$ $3.1 \mathrm{~mm}$ in grade 1 and grade 2 hydronephrosis respectively $(\mathrm{P}<0.05)$ (Table 1) (Fig. 1). There were significant corre- 

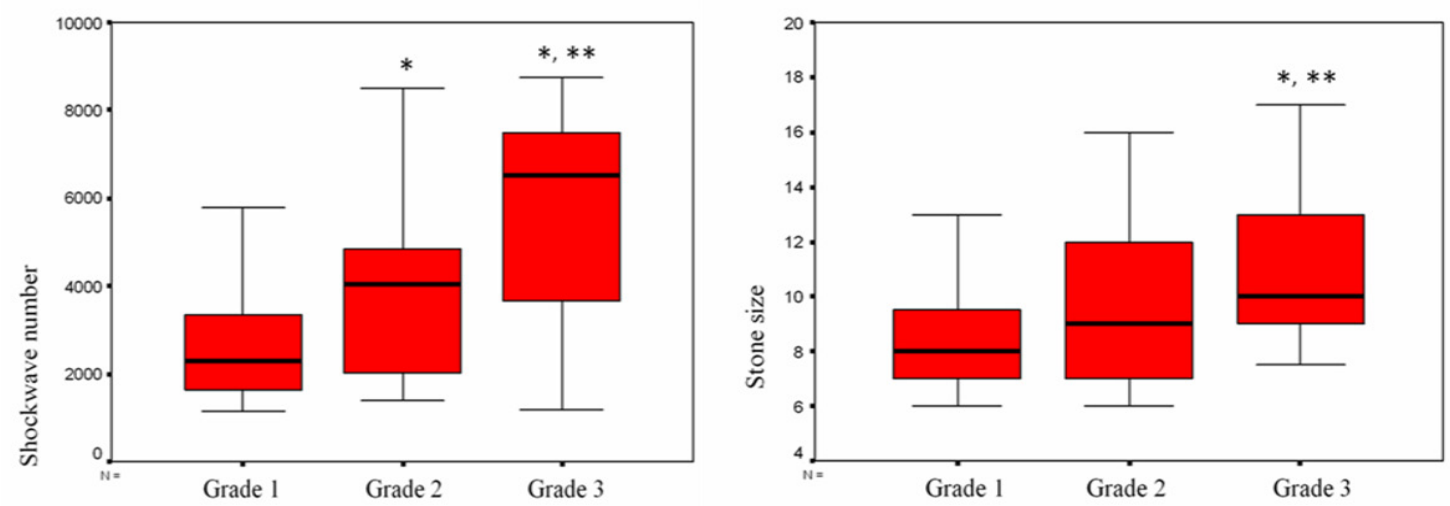

Figure 1. Shockwave/sessions number and stone size according to of hydronephrotic grades, $\mathrm{P}<0.05$; ${ }^{*} \mathrm{com}-$ pared to grade $1,{ }^{* *}$ compared to grade 2 .

lations between stone size and SD number $(\mathrm{r}=0.513, \mathrm{P}<$ $0.001)$, between stone size and session number $(\mathrm{r}=0.609, \mathrm{P}$ $<0.001$ ) (Table 3). The correlation between hydronephrotic grade, number of SW delivered and session number was also significant $(\mathrm{r}=0.472, \mathrm{P}<0.001$ and $\mathrm{r}=0.441, \mathrm{P}<0.001)$ (Table 3). There was no correlation between SSD and SW and session numbers $(\mathrm{r}=0.147, \mathrm{P}>0.05)$ (Table 3$)$. Fiftythree of 80 patients $(66 \%)$ had hematuria in their first urine. Two patient $(2.5 \%)$ developed pyelonephritis one of which was treated with parenteral antibiotics. Analgesics were required in 5 patients $(16 \%)$ for post-SWL pain.

\section{Discussion}

Many clinical studies performed over the last 20 years in order to define the optimal therapeutic approach for a given urinary stone. SWL is a safe, non-invasive and currently accepted treatment method of urolithiasis since satisfactory success rates with lower complication rate were reported. Reported clearance rates in ureteral stones remain about 80$90 \%$. The factors determining stone clearance and success rate after SWL were studied in order to define appropriate patients [6, 7]. Many factors influence the success of SWL, including BMI, stone size, stone location, stone composition, hydronephrotic grade, stone radiodensity, SSD and the type of lithotriptor used for SWL. Stone size and location are among the leading independent predictor factors. Concerning stone size, a larger size is associated with a higher risk for failure of treatment of urinary tract stones. It has been reported that patients with stones $>10 \mathrm{~mm}$ more frequently fail to be rendered stone-free by SWL. In addition to stone size and location, stone radiodensity in computed tomography has been also used to predict SWL outcomes. However, Hounsfield unit of the stone is not alone a definitive factor determining success rate and it should be combined with other parameters [8]. BMI is also used as a predictive factor which is related indirectly to the distance of the stone from

Table 2. Variables According to Stone Size (Mean \pm SD)

$$
\text { Group I } \leq 10 \mathrm{~mm}(\mathrm{~N}=\mathbf{5 7}) \quad \text { Group } \text { II }>10 \mathrm{~mm}(\mathrm{~N}=\mathbf{2 3})
$$

\begin{tabular}{lll}
\hline Gender (m/f) & $43 / 14$ & $13 / 10$ \\
Age (years) & $38.8 \pm 12.6$ & $35.2 \pm 10.0$ \\
Stone size (mm) & $7.9 \pm 1.4$ & $13.9 \pm 2.4$ \\
Shockwave number & $3,318 \pm 1,933$ & $5,036 \pm 2,346^{*}$ \\
SWL Session number & $1.4 \pm 0.6$ & $2.3 \pm 1.1^{*}$ \\
Skin-stone distance $(\mathrm{cm})$ & $9.4 \pm 1.8$ & $10.2 \pm 2.3$ \\
\hline
\end{tabular}

${ }^{*} \mathrm{P}<0.05$, compared to group I (independent samples test). 
Table 3. The Correlation of Variables With SWL Parameters

\begin{tabular}{lll}
\hline & \multicolumn{2}{l}{ Pearson correlation } \\
\cline { 2 - 3 } & r & P \\
& & \\
\hline Stone Diameter- Shock number & 0.513 & $0.000^{* *}$ \\
Stone Diameter- Session number & 0.609 & $0.000^{* *}$ \\
Hydronephrotic grade-Shock number & 0.472 & $0.000^{* *}$ \\
Hydronephrotic grade-Session number & 0.441 & $0.000^{* *}$ \\
Skin-stone distance- Shockwave number & 0.147 & $0.194^{*}$ \\
Skin-stone distance- Session number & 0.206 & $0.067^{*}$ \\
\hline
\end{tabular}

${ }^{*} \mathrm{P}>0.05,{ }^{* *} \mathrm{P}<0.001$

the skin, which reflects the SW path in the body [6]. Since BMI may not directly reflect central body fat distribution, it does not accurately predict the distance of SW source to stone. Therefore, SSD seems to be a more direct measurement of the effect of body build on SWL outcome than is BMI. Many investigators have reported that SSD is a significant predictor in ureteral stones. Their result supported that SSD could predict SWL stone free rates [9]. An SSD $>110 \mathrm{~mm}$ was reported to be a significant predictor of an unfavorable outcome after SWL whereas SSD of $<90 \mathrm{~mm}$ can predict SWL success $[9,10]$.

In our series, SSD was not a significant predictor of SW and session numbers. However, we may not have had enough data to reveal the importance of SSD in the management of ureteral stones. Beside the above mentioned predictive factors, there are also secondary signs to affect the outcome of SWL such as hydroureter, hydronephrosis, periureteral edema, and unilateral renal enlargement. Whether these secondary signs in patients with ureteral stones affect outcome in SWL treatment remains also controversial [11]. Particularly, the hydronephrosis effect on SWL outcomes has been widely studied. Many studies showed that the likelihood of SWL treatment failure increases with more severe obstruction $[12,13]$. It was reported that in patients with proximal and distal ureteral stone the SWL outcome was affected by hydronephrotic grade $[14,15]$. In contrast to these reports, some authors concluded that urinary obstruction does not affect the success in terms of stone clearance with SWL [16, 17]. They claimed that neither the presence nor the grade of hydronephrosis had a significant impact on SWL outcome [18]. In a previous study of SWL for proximal ureteral stones, the differences between non-hydronephrotic and hydronephrotic groups in terms of stone size and SWs applied, were not significant [7]. Even after stratifying patients for different grades of hydronephrosis (grade 1-3) again, differences were not statistically significant. In contrast to these findings, in a very recent study, the data of 153 patients undergoing SWL for stones in upper, mid and lower ureteral locations were retrospectively reviewed and authors found out that stone size is an independent predictive factor influencing failure of SWL for ureteral stones. All the secondary signs including hydronephrosis showed statistically significant differences in terms of SWL outcomes in this series [19]. Although our series had limited number of patients, we found statistically significant differences between hydronephrotic grades in terms of the number of sessions and number of SWs and stone size in patients with different grades of hydronephrosis. As the previous studies reported that ureteral obstruction resulted in decreased peristalsis and decreased pressure, affecting stones migration, the negative effect of hydronephrosis on stone clearance after SWL seems plausible [20]. We also speculate that the obstruction is more easily resolved in patients with smaller stones whereas it is severe and persistent in larger stones which creates a vicious circle with the higher grade of obstruction against SWL outcomes. There are also limitations to our study. It is in retrospective nature, the study population has a limited number to reveal the importance of SSD and, we did not evaluate time to stone clearance.

\section{Conclusion}

Stone size is an independent predictive factor influencing SWL session and SW numbers in the treatment of ureteral stones. In addition to stone size, the grade of hydronephrosis is also an independent predictive factor for SWL variables. However, SSD was not found to be predictive in the study. Besides, the stone size has a negative effect on hydronephro- 
sis grade.

\section{References}

1. Chaussy C, Schmiedt E, Jocham D, Brendel W, Forssmann B, Walther V. First clinical experience with extracorporeally induced destruction of kidney stones by shock waves. J Urol. 1982;127(3):417-420.

2. Saw KC, McAteer JA, Fineberg NS, Monga AG, Chua GT, Lingeman JE, Williams JC, Jr. Calcium stone fragility is predicted by helical CT attenuation values. J Endourol. 2000;14(6):471-474.

3. Turk C, Knoll T, Petrik A, Sarica K, Straub MC. Seitz Guidelines on Urolithiasis European Association of Urology (EAU). 2012.

4. Robert M, Delbos O, Guiter J, Grasset D. In situ piezoelectric extracorporeal shock wave lithotripsy of ureteric stones. Br J Urol. 1995;76(4):435-439.

5. Lingeman JE, Matlaga BR. Surgical management of upper urinary tract calculi. In: Wein AJ, Kavoussi LR, Novick AC, Partin AW, Peters CA, editors. Campbell-Walsh urology. 10th ed. Philadelphia: Saunders; 2010;1375-1377.

6. Pareek G, Armenakas NA, Panagopoulos G, Bruno JJ, Fracchia JA. Extracorporeal shock wave lithotripsy success based on body mass index and Hounsfield units. Urology. 2005;65(1):33-36.

7. Seitz C, Fajkovic H, Waldert M, Tanovic E, Remzi M, Kramer G, Marberger M. Extracorporeal shock wave lithotripsy in the treatment of proximal ureteral stones: Does the presence and degree of hydronephrosis affect success? Eur Urol. 2006;49(2):378-383.

8. Krishnamurthy MS, Ferucci PG, Sankey N, Chandhoke PS. Is stone radiodensity a useful parameter for predicting outcome of extracorporeal shockwave lithotripsy for stones $<$ or $=2 \mathrm{~cm}$ ? Int Braz J Urol. 2005;31(1):3-8; discussion 9.

9. Perks AE, Schuler TD, Lee J, Ghiculete D, Chung DG, RJ DAH, Pace KT. Stone attenuation and skin-to-stone distance on computed tomography predicts for stone fragmentation by shock wave lithotripsy. Urology. 2008;72(4):765-769.

10. Wiesenthal JD, Ghiculete D, RJ DAH, Pace KT. Evaluating the importance of mean stone density and skinto-stone distance in predicting successful shock wave lithotripsy of renal and ureteric calculi. Urol Res. 2010;38(4):307-313.

11. Ege G, Akman H, Kuzucu K, Yildiz S. Acute ureterolithiasis: incidence of secondary signs on unenhanced helical CT and influence on patient management. Clin Radiol. 2003;58(12):990-994.

12. Delakas D, Karyotis I, Daskalopoulos G, Lianos E, Mavromanolakis E. Independent predictors of failure of shockwave lithotripsy for ureteral stones employing a second-generation lithotripter. J Endourol. 2003;17(4):201-205.

13. el-Assmy A, el-Nahas AR, Youssef RF, el-Hefnawy AS, Sheir KZ. Does degree of hydronephrosis affect success of extracorporeal shock wave lithotripsy for distal ureteral stones? Urology. 2007;69(3):431-435.

14. Hsiao HL, Huang SP, Wu WJ, Lee YC, Li WM, Chou $\mathrm{YH}$, Chang AW, et al. Impact of hydronephrosis on treatment outcome of solitary proximal ureteral stone after extracorporeal shock wave lithotripsy. Kaohsiung J Med Sci. 2008;24(10):507-513.

15. Turna B, Akbay K, Ekren F, Nazli O, Apaydin E, Semerci B, Gunaydin G, et al. Comparative study of extracorporeal shock wave lithotripsy outcomes for proximal and distal ureteric stones. Int Urol Nephrol. 2008;40(1):2329.

16. Kirkali Z, Esen AA, Celebi I, Guler C. Are obstructing ureteral stones more difficult to treat with extracorporeal electromagnetic shock wave lithotripsy? J Endourol. 1993;7(4):277-279.

17. Demirbas M, Kose AC, Samli M, Guler C, Kara T, Karalar M. Extracorporeal shockwave lithotripsy for solitary distal ureteral stones: does the degree of urinary obstruction affect success? J Endourol. 2004;18(3):237-240.

18. Singh I, Gupta NP, Hemal AK, Dogra PN, Ansari MS, Seth A, Aron M. Impact of power index, hydroureteronephrosis, stone size, and composition on the efficacy of in situ boosted ESWL for primary proximal ureteral calculi. Urology. 2001;58(1):16-22.

19. Choi JW, Song PH, Kim HT. Predictive factors of the outcome of extracorporeal shockwave lithotripsy for ureteral stones. Korean J Urol. 2012;53(6):424-430.

20. El-Assmy A, El-Nahas AR, Youssef RF, El-Hefnawy AS, Sheir KZ. Impact of the degree of hydronephrosis on the efficacy of in situ extracorporeal shock-wave lithotripsy for proximal ureteral calculi. Scand J Urol Nephrol. 2007;41(3):208-213. 